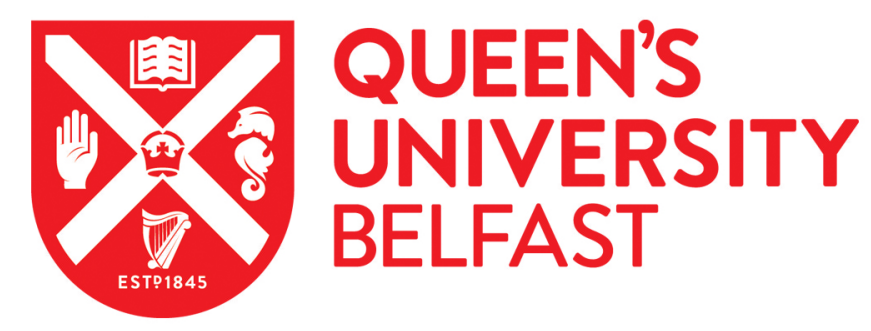

\title{
The Influence of External and Internal Stakeholder Pressures on the Implementation of Upstream Environmental Supply Chain Practices
}

Graham, S. (2020). The Influence of External and Internal Stakeholder Pressures on the Implementation of Upstream Environmental Supply Chain Practices. Business \& Society, 59(2), 351-383.

https://doi.org/10.1177/0007650317745636

Published in:

Business \& Society

Document Version:

Peer reviewed version

Queen's University Belfast - Research Portal:

Link to publication record in Queen's University Belfast Research Portal

Publisher rights

Copyright 2017 SAGE

This work is made available online in accordance with the publisher's policies. Please refer to any applicable terms of use of the publisher.

\section{General rights}

Copyright for the publications made accessible via the Queen's University Belfast Research Portal is retained by the author(s) and / or other copyright owners and it is a condition of accessing these publications that users recognise and abide by the legal requirements associated with these rights.

Take down policy

The Research Portal is Queen's institutional repository that provides access to Queen's research output. Every effort has been made to ensure that content in the Research Portal does not infringe any person's rights, or applicable UK laws. If you discover content in the Research Portal that you believe breaches copyright or violates any law, please contact openaccess@qub.ac.uk. 
The environmental impact generated by business has emerged as a key area of research within the field of operations and supply chain management over the last three decades (Daily et al., 2012; Kumar et al., 2012). Global concerns over environmental challenges facing the planet have prompted a progressively loudening outcry from different stakeholder groups, affecting the institutional environments in which companies operate and heightening the pressure on companies to manage the environmental impact of not only their own operations but also their wider supply chain's (Ayuso et al., 2014; Guenther et al., 2016). Environmental supply chain management (ESCM) involves the incorporation of environmental concerns into activities at different stages of the supply chain from upstream suppliers, to downstream customers (Zhu et al., 2012). In practice, broad variations of this exist with some companies pursuing more extensive integration of environmental efforts throughout their supply chains than others (Blome et al., 2012; Jacobs et al., 2016). Despite the variations in practical implementation, it is now generally accepted that companies need to pay attention to the environmental impact of processes and practices throughout their supply chain in order to respond to stakeholder pressures.

Broadly defined as anyone who has an interest or stake in what a company does, the range of stakeholder groups pressuring companies to be more environmentally responsible has increased in recent years (Gondivan, 2017; Kannan, 2017; Moriarty, 2014; Simpson and Sroufe, 2014). Collectively, these pressures have been highlighted as one of the main driving forces behind an increase in practical environmental responses. Operating within a broad and complex network of stakeholder constituents, companies can experience tension between the demands of different stakeholder groups (Hoffman, 2001). For example, a practical response to pressures to become more environmentally responsible may require additional investment in new technologies or practices, potentially conflicting with pressures from shareholders to maximise profits (Walley and Whitehead, 1994). On the other hand, failure to respond to 
stakeholder environmental concerns may hinder the long-term success of the company, which may be more damaging to shareholder interests (Kannan, 2017). Further, others highlight the potential for sources of competitive advantage to be attained through investment in environmental efforts (Hart, 1995; Hart and Dowell, 2011), suggesting that these efforts may support shareholder demands. The level of practical response to environmental pressures is likely to be influenced by the level of perceived benefit of investing in environmental efforts from within the company. This is reflected in the strategic environmental approach or response of the company and some studies note that the influence of certain stakeholder groups may be stronger for companies adopting particular strategic responses (Buysse and Verbeke, 2003; Henriques and Sadorsky, 1999; Liu et al., 2017).

Strategic responses to environmental pressures can be considered on a spectrum ranging from reactive to proactive (Buysse and Verbeke, 2003; Delmas et al., 2011; Dubey et al., 2015; Henriques and Sadorsky, 1999). Companies adopting a reactive response will seek to comply with coercive pressures such as legislations imposed on them by regulatory bodies (Buysse and Verbeke, 2003; Sarkis et al., 2010). They adopt a fire fighting approach whereby environmental concerns are dealt with as and when they become problematic, in a post-hoc manner (Buysse and Verbeke, 2003; Munguia et al., 2010). Thus, they seek to control levels of pollution or environmental impact in accordance with legislations as opposed to pre-empting and preventing them (Hart, 1995). At the other end of the spectrum, companies adopting a proactive approach express a much stronger commitment to tackling environmental concerns. This commitment is demonstrated through their willingness to go beyond compliance with required levels or standards (Garces-Ayerbe et al., 2012; Hamann et al., 2015). A proactive approach is indicative of a level of commitment from internal stakeholders such as top management and employees towards environmental concerns and challenges (Liu et al., 2017). As companies 
become more environmentally proactive, they seek to improve the environmental performance of not only their own production processes but also that of their supply chain (Hart, 1995).

A number of studies highlight a link between the environmental response or strategy developed by stakeholders within the company (e.g. managers and employees) and the influence of pressure from stakeholders outside of the company (Buysse and Verbeke, 2003; Henriques and Sadorsky, 1999; Liu et al., 2017). For example, proactive companies may be influenced by a broader range of stakeholders than reactive companies as they perceive environmental concerns to be of strategic importance and seek to engage with stakeholders to tackle these concerns (Hart, 1995; Liu et al., 2017). While some studies suggest links between certain stakeholder groups and particular environmental responses, the influence of individual stakeholder groups on specific environmental practices has not received extensive research attention (Tachizawa et al., 2015). Further, while some existing studies consider the influence of stakeholder pressure on environmental strategy or the influence of environmental strategy on environmental practices (Bowen et al., 2001; Buysse and Verbeke, 2003; Graham and Potter, 2015; Henriques and Sadorsky, 1999), few studies appear to consider the combined influence of external stakeholder pressure and internal strategic response on the practical implementation of environmental practices (Sarkis et al., 2010). This is an important consideration as it connects the response of internal stakeholders such as top management and employees to the pressures from external stakeholders in generating a practical environmental response. Thus, the level of practical response to external environmental pressures is likely to be influenced by the level of strategic importance given to environmental concerns by stakeholders within the company as reflected in their environmental strategy or response (Simpson and Sroufe, 2014; Tachizawa et al., 2015).

Competitors are an external stakeholder group that hold the potential to indirectly influence what a company does by affecting the institutional environment in which they operate 
through influencing public opinion on legitimate environmental practices (Compagni et al., 2015; Sarkis et al., 2010; Su and Tsang, 2015; Tachizawa et al. 2015). Few studies appear to consider the influence of this particular stakeholder group on the development of a practical environmental response within companies (Hofer et al., 2012; Tachizawa et al., 2015; Zailani et al., 2012). It is important to address this omission in order to further understand the key antecedents to environmental supply chain practices. Further, some studies suggest that environmentally proactive companies may pay greater attention to pressures from competitors in developing their response to environmental concerns than reactive companies (Bansal, 2005; Tachizawa et al., 2015). A key reason for this is that reactive companies are influenced more extensively by coercive regulatory pressures, whilst proactive companies have already gone beyond meeting the demands of these pressures and are influenced by a broader range of stakeholders (Bansal, 2005; Buysse and Verbeke, 2003; Tachizawa et al., 2005). Further, environmentally proactive companies may perceive potential sources of competitive advantage from environmental efforts and will thus be interested in the environmental behaviour of their competitors in shaping public opinion in this regard.

In response to recent calls for research to further develop understanding of the key antecedents to the implementation of environmental supply chain practices (Daily et al., 2012; Dubey et al., 2015; Murillo-Luna et al., 2011), this study addresses some of the aforementioned gaps in the existing literature on environmental supply chain management. As the implementation of more advanced environmental practices becomes more prominent, it is helpful to understand the key influencing factors driving companies to invest more extensively in managing the environmental impact of their supply chains (Zailani et al., 2012). Building upon the existing research base outlining stakeholder pressure and environmental strategy as key antecedents to environmental practices, this study considers the influence of competitor pressure and proactive environmental strategy on the implementation of environmental 
practices upstream in the supply chain. Upstream practices involve companies extending their environmental efforts to include suppliers, thus, taking responsibility for environmental impacts upstream in their supply chain (Bode and Wagner, 2015). The complexity of managing a number of different suppliers upstream in the supply chain can lead to an increase in environmental challenges for companies if suppliers have poor environmental performance. Due to the increased level of accountability expected of companies regarding the environmental impact of their entire supply chain, the implementation of environmental practices upstream with suppliers is an important area requiring further research and development (Ayuso et al., 2014; Bode and Wagner, 2015; Guenther et al., 2016).

This article addresses two research questions; namely, (1) do external competitive pressures influence the development of a proactive environmental strategy and the practical implementation of upstream environmental practices? (2) does the existence of a proactive environmental strategy mediate the relationship between external competitive pressures and upstream environmental practices? Hypotheses are developed and tested using data collected from 149 food manufacturing companies located within the UK. This article makes three important contributions to the existing literature on ESCM. First, it extends the application of stakeholder theory in the context of ESCM by considering the influence of competitive pressure on environmental strategy and practices. Second, it builds upon the studies highlighting the importance of internal response to external pressures by investigating the influence of competitive pressure on the development of a proactive environmental strategy. Third, by considering the combined influence of external competitive pressures and internal environmental strategy in the implementation of upstream environmental practices, it responds to a number of recent calls for future research to consider both internal and external drivers of ESCM (Hofer et al., 2012; Sarkis et al., 2010; Zailani et al., 2012). The following sections 
outline the theoretical background, hypothesis development, research methodology, analysis and discussion.

\section{Theoretical Background}

Stakeholder theory underpins a number of studies seeking to understand the motivations for companies behaving in a particular way. It is extensively applied in studies considering the antecedents of environmental activity at both the company and supply chain level (Buysse and Verbeke, 2003; Gualandris et al., 2015; Tachizawa et al., 2015; Zhu et al., 2012). Substantial empirical evidence exists in support of the role of different stakeholder groups as drivers of environmental activities within companies and supply chains (i.e. Buysse and Verbeke, 2003; Sarkis et al., 2010; Tachizawa et al., 2015). Building on this, recent studies call for further research to consider the influence of lesser explored stakeholder groups as well as the combined influence of the internal response from companies to external pressures in driving environmental practices (Hofer et al., 2012; Sarkis et al., 2010; Tachizawa et al., 2015). The following section provides a general overview of stakeholder theory and its application in environmental management studies.

\section{Stakeholder Theory}

The long term survival of companies depends in part on their ability to effectively manage relationships with the broad and complex network of stakeholders within which they operate (Kannan, 2017). A stakeholder can be defined as "any group or individual who can affect or is

affected by the achievement of an organization's objectives" (Freeman, 1984: 46). In identifying the specific groups falling within this definition, some distinguish between internal 
and external stakeholder groups. The former includes groups located within a company such as shareholders, managers and employees while the latter includes groups outside the company such as customers, local communities, governments, environmental groups and competitors (Ayuso et al., 2014; Gondivan, 2017; Sarkis et al., 2010). In responding to extensive pressures from a wide range of different groups, Mitchell et al. (1997) suggest that firms should pay attention to the groups considered to be most salient in terms of their power, legitimacy and the urgency of their request. Pressure from a range of stakeholder groups is an important motivation for the implementation of various environmental strategies and practices (Buysse and Verbeke, 2003; Guenther et al., 2016; Sarkis et al., 2010). Companies respond to pressures to reduce negative environmental impacts throughout their production processes both internally and at the supply chain level by developing environmental capabilities through the implementation of a range of environmental practices (Pullman and Wikoff, 2017).

Extensive empirical support has been generated in support of the important role played by stakeholders, both individually and collectively in driving environmental efforts within companies (i.e. Buysse and Verbeke, 2003; Sarkis et al., 2010; Tachizawa et al., 2015). Different stakeholder groups place different demands and expectations on companies and companies respond in heterogeneous ways in accordance with the power, legitimacy and urgency with which they regard a particular demand (Mitchell et al., 1997). These pressures can be categorised as coercive or non-coercive pressures within the external environment and they are normally targeted at a group of companies within a particular industry as opposed to an individual company (Tachizawa et al., 2015). The main stakeholder source of coercive pressures is government and regulators, but these pressures may also derive from powerful firms within the industry who exert a degree of political influence or other external stakeholders such as customers and suppliers (Darnall et al., 2008; Liu et al., 2010). A number of environmental legislations have emerged in recent years, pressuring companies to comply with 
certain standards or levels in terms of the environmental impact of their production processes. Non-compliance may result in penalties or fines for companies, so it is in their interest to meet the requirements of these groups who are pressuring them in a somewhat coercive manner (Tachizawa et al., 2015). However, concerns have been raised about the effectiveness of this pressure source in achieving long term solutions that improve the environmental impact of business. If companies are constantly responding to coercive pressures, they may be pushed towards practice validation rather than practice improvement (Simpson and Sroufe, 2014). In other words, it might hinder them from developing more effective preventative solutions that generate greater benefits in the long-term (Liu et al., 2017).

Non-coercive pressures can be competitive or normative in nature (Tachizawa et al., 2015). Competitive pressures mainly arise from a company's perception of their competitors' success resulting from certain practices (Di Maggio and Powell, 1983; Heras-Saizarbortoria et al., 2011; Liu et al., 2010). As the number of competitors adopting environmental practices increases, there is pressure for other companies within the same market to follow suit (Compagni et al., 2015). A company may seek to imitate these practices to reduce risk and achieve legitimacy by following the lead of companies they perceive as successful, or because they do not fully understand the requirements for sustained success themselves (Braunscheidel et al., 2011; Di Maggio and Powell, 1983; Liu et al., 2010). Normative pressures arise from industry or sector members attempting to define the way in which productive activity should be conducted within their area (Darnall et al., 2008; Di Maggio and Powell, 1983). This results in the development of sets of expectations for specific organisational contexts which are transferred through inter-organisational channels to the point where they become shared norms (Liu et al., 2010; Zailani et al., 2012). Companies within organisational contexts affected by these norms will seek to conform to them in order to maintain their legitimacy (Liu et al., 2010; Zsidisin et al., 2005). 
Companies will be influenced in different ways by these different types of pressure deriving from key stakeholder groups. For example, companies who already meet or exceed the requirements of legislations will not be influenced as strongly by coercive pressures deriving from regulatory stakeholder groups as those who do not meet these requirements (Buysse and Verbeke, 2003; Henriques and Sadorsky, 1999). Thus, the position or viewpoint of internal primary stakeholders who control resources and determine the strategic direction of the company plays an important role in developing the practical response to external pressures. Recent studies highlight the importance of considering the response developed by internal stakeholder groups to environmental concerns in understanding the heterogeneity of practical responses to external stakeholder pressures (Hofer et al., 2012; Liu et al., 2017; Sarkis et al., 2010). The following section presents the development of the hypotheses tested in this study.

\section{Hypothesis Development}

In order to address the research questions underpinning this study, four hypotheses were developed. The first considers the independent influence of a proactive environmental strategy on upstream environmental practices with suppliers. The second considers the independent influence of external competitive pressure on the adoption of a proactive environmental strategy. The third considers the direct influence of competitive pressure on upstream environmental practices. The fourth considers the combined influence of competitive pressure and proactive environmental strategy on upstream environmental practices with suppliers. The following sections will discuss each of the concepts adopted in this study and their hypothesised relationships with each other.

The link between proactive environmental strategy and upstream environmental practices 
A proactive environmental strategy can be defined as " $a$ tendency to go further than complying with legislation or the industry standard” (Garces-Ayerbe et al., 2012: 190). It represents a commitment to environmental activity at a strategic level, which cascades down to the operations and supply chain level, influencing the practices and processes adopted. A proactive environmental strategy is developed and implemented by internal stakeholders such as owners, directors, managers and employees (Bowen et al., 2001). It implies a level of commitment to tackling environmental concerns from within the company which suggests that these issues are held in high regard by the internal stakeholders (Henriques and Sadorsky, 1999; Liu et al., 2017). Thus, the existence of a proactive strategy reflects a somewhat positive approach and commitment to tackling environmental concerns from within the company.

Strategic environmental orientation influences the practical response of companies to environmental challenges. For example, companies who develop a more reactive orientation tend to implement less advanced environmental practices that meet the requirements of the coercive pressures being imposed on them (Simpson and Sroufe, 2014). They tend to deal with environmental concerns as and when they arise rather than pre-empting concerns and redesigning practices and processes to prevent their occurrence (Hart, 1995). Their focus tends to be on dealing with their own environmental impact and responding to the immediate pressures facing their company, as opposed to developing a broader supply chain level response (Simpson and Sroufe, 2014). On the other hand, proactive companies tend to go beyond compliance in their practical response to environmental concerns and implement more advanced environmental practices internally and at the supply chain level. A number of studies have generated empirical support for a proactive environmental strategy and a practical response at the supply chain level (Bowen et al., 2001; Graham and Potter, 2015). Environmental concerns emanating from upstream in the supply chain are an important starting 
point for proactive companies pursuing more environmentally responsible supply chains (Bode and Wagner, 2015). Some of the upstream practices outlined in the environmental management literature are presented in the following section.

Upstream environmental practices with suppliers

A wide range of environmental supply chain practices have been considered in the operations and supply chain management literature to date. Of the studies considering environmental practices that emanate from a proactive environmental strategy, some adopt an internal focus, with emphasis on practices that are implemented within the company's internal operations (Sarkis et al., 2010; Zailani et al., 2012), others adopt a more integrative approach whereby practices implemented at different stages of the supply chain are considered (Gonzalez-Benito and Gonzalez-Benito 2006; Graham and Potter 2015; Paulraj, 2008). Fewer studies focus on the implementation of a proactive strategy through environmental practices at a specific stage of the supply chain. Bowen et al. (2001) consider the influence of a proactive environmental strategy on product and process-based green supply practices. Building on this, an upstream focus on environmental practices with suppliers is adopted in this study.

Extension of environmental practices to the supply chain level may be indicative of more proactive strategies as companies seek to address the environmental impact of not only their own practices but also those of their suppliers (Hart, 1995; Hart and Dowell, 2011). Key upstream practices identified within the literature are, supplier selection, supplier monitoring and supplier collaboration (Paulraj, 2008; Tachizawa et al., 2015; Vachon and Klassen, 2008). Supplier selection involves consideration of environmental criteria in the selection of suppliers with whom the company will work (Paulraj, 2008). This enables the company to identify suppliers whose practices they can align with their own proactive strategy and practices. 
Supplier monitoring seeks to ensure a supplier's compliance with the company's environmental expectations or requirements (Vachon, 2006). This may involve site visits or periodic assessment of certain measures decided between the company and their supplier. It enables the company to set environmental goals for their supply chain, and facilitates improvement through continuous measuring and assessment. Supplier collaboration is distinct from selection and monitoring as it requires input from the supplier in improving the environmental performance of the supply chain (Paulraj, 2008; Tachizawa et al., 2015). A relationship with the collaborative party can facilitate the information sharing and understanding of respective capabilities required for this environmental practice (Vachon and Klassen, 2008). A proactive environmental strategy may be practically implemented through environmental practices upstream in the supply chain (Bowen et al., 2001). Thus, the following hypothesis is developed;

H1: A proactive environmental strategy is positively linked to upstream environmental practices with suppliers.

The influence of competitive pressure on environmental proactivity and upstream environmental practices

The influence of different stakeholder pressures on environmental strategies and practices has been considered in a number of studies (Buysse and Verbeke, 2003; Henriques and Sadorsky, 1999; Tachizawa et al., 2015). Some note differences in the influence of coercive and noncoercive pressures on certain strategies or practices (Buysse and Verbeke, 2003; Paulraj, 2008; Tachizawa et al., 2015). Stakeholder pressures that are more coercive in nature have been linked to reactive environmental strategies, while non-coercive pressures have been linked to 
proactive environmental strategies (Buysse and Verbeke, 2003; Tachizawa et al., 2015; Zailani et al., 2012). A study conducted by Henriques and Sadorsky (1999) found that regulatory and media stakeholder groups exert a strong influence on environmentally reactive companies but not environmentally proactive companies. The reason for this is that reactive companies are doing the bare minimum to avoid fines or negative publicity, whereas proactive companies are exceeding the expectations of these groups and therefore do not need to be as sensitive to the pressures coming from them. Proactive companies may be more responsive to non-coercive pressures coming from a broader range of stakeholder groups including customers and competitors (Tachizawa et al., 2015).

The specific drivers of a proactive environmental strategy have not been considered extensively in the literature. Zailani et al. (2012) present eco-design as an internally oriented proactive practice and provide empirical support for the influence of coercive and normative pressures on its implementation. Buysse and Verbeke (2003) present support for the diminishing influence of regulatory pressures as companies adopt more proactive environmental strategies, suggesting that other external pressures increase in importance as these strategies are developed and implemented. Garces-Ayerbe et al. (2012) consider the collective influence of a range of stakeholder groups on the adoption of a proactive environmental strategy and provide support for a link between higher levels of pressure and greater proactivity. The independent influence of competitive pressures on both environmental strategy and practices does not appear to have been considered extensively to date (Hofer et al., 2012). This is an important consideration, because the implementation of a proactive strategy suggests that the company perceives there to be some form of competitive benefit from environmental activity (Bansal, 2005; Hamann et al., 2015; Hart and Dowell, 2011). Competitive environmental pressures emanate from the external environment where rival companies adopt environmental strategies and practices (Hofer et al., 2012). According to 
stakeholder theory, this leads to the adoption of these strategies and practices by other companies who seek to remain legitimate in the eyes of various stakeholders (Ayuso et al., 2014; Gualandris et al, 2015). Thus, they are being driven by competitive opportunities and threats deriving from their external environment rather than the legislations and standards imposed on them by coercive pressures (Bansal, 2005). Of the studies that have considered the antecedents of proactive strategies and practices, the majority find support for higher levels of external pressure leading to an increase in proactivity (Buysse and Verbeke, 2003; GarcesAyerbe et al., 2012; Tachizawa et al., 2015; Zailani et al., 2012). Consistent with this, it is expected that higher levels of competitive pressure will be associated with an increase in proactivity, both at the strategic level and in terms of a practical response at the supply chain level. This is reflected in the following hypotheses;

H2: Competitive pressure positively influences the adoption of a proactive environmental strategy.

H3: Competitive pressure positively influences the implementation of upstream environmental practices with suppliers.

The combined influence of external competitive pressure and internal strategy on the implementation of upstream environmental practices

A number of recent studies highlight the importance of understanding both external and internal drivers of environmental activity (Dubey et al., 2015; Wu et al., 2012; Zailani et al., 2012). Companies facing similar levels of external pressure often respond differently, calling attention to a range of internal factors that may influence these heterogeneous responses (Sarkis et al., 
2010). While external pressures may provoke initial environmental responses, the level of practical response to these pressures is likely to be either constrained or facilitated by a range of internal factors (Bansal, 2005; Sarkis et al., 2010; Heras-Saizarbitoria et al., 2011; Tachizawa et al., 2015). The environmental strategy or response developed by internal stakeholders plays an especially important role as it influences the level of regard in which environmental concerns are held within the company. Thus, the influence of external pressure alone might not be enough to drive a practical response, but the importance given to environmental concerns by stakeholders within the company will play a key role in the development of this response (Sarkis et al., 2010; Garces-Ayerbe et al., 2012).

Companies adopting a reactive environmental strategy develop their practical environmental response to meet the minimum requirements imposed on them by external regulatory stakeholders (Buysse and Verbeke, 2003). Thus, their practical response is usually targeted at the internal, operations level whereby they seek to control their own environmental impact in accordance with the guidelines and restrictions imposed on them by coercive pressures. On the other hand, proactive environmental strategy is often linked to the development of a more advanced practical response at the supply chain level (Bowen et al., 2001; Gonzalez-Benito and Gonzalez-Benito, 2006; Graham and Potter, 2015). Thus, proactive companies express a higher level of commitment to tackling environmental concerns, not only through internal environmental practices, but also through broader supply chain level practices (Hart, 1995; Hart and Dowell, 2011).

The level of commitment to environmental concerns expressed through environmental strategy will influence the perception and response to pressures deriving from the external environment. For example, the development of an advanced practical response to external pressures may be constrained by a reactive strategy, whereby companies just seek to comply with the targets imposed on them by regulatory bodies (Buysse and Verbeke, 2003). On the 
other hand, proactive companies consider a wider range of stakeholders to be important than reactive companies (Liu et al., 2017). Competitive pressures, in particular, exert more influence on proactive companies than reactive companies as the former perceive there to be competitive benefits inherent in developing their environmental response (Bansal, 2005; Tachizawa et al., 2015). Thus, the existence of a proactive environmental strategy should be conducive in the development of an advanced practical response to external pressures deriving from competitors as proactive companies will perceive potential benefits to be attained through the development of this response (Hart, 1995). This is reflected in the following hypothesis;

H4: A proactive environmental strategy mediates the relationship between competitive pressure and upstream environmental practices with suppliers.

\section{Research Methodology}

\section{Data collection}

Data were collected via a postal survey of the UK food industry. The UK provides an interesting context for the research as it is a developed economy with well-established environmental regulations in place. Thus, environmental management has been prominent within this context for a long time and proactive environmental strategies exist to a greater extent than in developing countries. The focus on a single-country context means that differing regulations will not influence results (Marshall et al., 2015; Pagell and Gobeli, 2009; Sarkis et al., 2010). The food industry faces a range of unique environmental challenges and calls have been made for studies to conduct further research within this context (Darkow et al., 2015; Mattas and Tsakiridou, 2010; New, 2015; Pullman and Wikoff, 2017). Further, research 
specific to this industry is important as it is the largest manufacturing sector in both developed and developing countries, playing a key role in terms of employment and economic development (Agustina et al., 2014; Li et al., 2014).

As a first step in the survey development process, five semi-structured interviews were conducted with managers of food manufacturing companies from different sub-industry backgrounds, including red meat, prepared vegetables, bakery, poultry and potatoes. This enabled some of the key environmental challenges as well as the dominant environmental practices within the context to be highlighted. This qualitative data was corroborated with data from online sources such as the Food and Drink Federation (FDF) and the Department for Environment, Food and Rural Affairs (DEFRA), as well as the literature on environmental issues in the food industry. Established measures from existing environmental management research were sought and used where available. Upon completion of the survey instrument, it was subjected to a series of pilot tests with six further managers and six senior academics in the area of operations management (Drucker, 2005).

The sampling frame included operations and production managers from UK food manufacturing companies. Contact and company information was purchased from William Reed media. Responses were sought from medium (50-249 employees) to large $(>250$ employees) companies, as they are likely to experience higher levels of environmental pressure than smaller companies (Awaysheh and Klassen, 2010; Darnall et al., 2010). The survey was sent to 1200 potential key informants in companies operating within the Standard Industrial Classification (SIC) DA 15 which includes a number of sub-industries such as meat, dairy, animal feed, grain, starch, fruit and vegetables. Distribution of the survey was conducted in accordance with Dillman's (2007) tailored design method. In addition to this, follow up phone calls were used to encourage further responses (Forza, 2002). 
A total of 149 complete and useable responses were obtained generating an effective response rate of $12.4 \%$. While somewhat low, the number of responses was considered sufficient for the analyses conducted. Guidelines from Hair et al. (2006) about the number of responses needed for regression analyses were adhered to, taking into consideration the number of variables included in the model and the number of items comprising them. The number of responses exceeded the required limits suggested in these guidelines. Further, it is consistent with other studies in the area of environmental operations and supply chain management that have obtained effective numbers of responses ranging between 71 to 218 (Braunscheidel and Suresh, 2009; Sarkis et al., 2010; Simpson and Sroufe, 2014; Tachizawa et al., 2015). Around 150 responses is typical in environmental management studies and considered acceptable for the analysis used (Hair et al., 2006; Sarkis et al., 2010; Simpson and Sroufe, 2014).

A number of sub-industry groups were represented in responses including, processed food $(20.8 \%)$, beverages (18.1\%), meat (17.4\%), dairy (14.1\%) and other (29.6\%). In assessing for non-response bias, a comparison of early and late responders was conducted (Armstrong and Overton, 1977). As an additional test of non-response, the size and age of responding companies was compared with non-responding companies from within the sample frame using an independent samples $t$-test. The results were consistent with the early and late responder comparison tests, suggesting that non-response bias does not pose a concern as there did not appear to be any significant differences between the two groups in either case.

\section{Measures}

To ensure a higher level of validity, the constructs were operationalised using pre-existing measures, where available. One new measure was developed to measure the construct of competitive pressure. To facilitate this development, insight was drawn from the literature as 
well as established guidelines on scale development (Chen and Paulraj, 2004; Hair et al., 2006). Multiple indicators were used to measure all of the constructs. Responses were anchored from either "strongly agree" to "strongly disagree" or "not at all" to "a very great extent" using a seven point Likert scale. All of the measures and their comprising items are outlined in Appendix 1.

\section{Independent variables}

The construct proactive environmental strategy acts as both an independent and dependent variable in the framework. This was measured using a five-item scale adapted from Bowen et al. (2001). Managers indicated the extent to which they give priority to environmental issues at different levels of management; lead industry on environmental issues; go beyond compliance with legislations; and manage environmental risks affecting their business. A new three-item measure was developed to assess the level of competitive pressure in the external environment. Managers indicated the extent to which environmental concerns are being taken seriously by their competitors; the extent to which these competitors are implementing environmental practices; and the extent to which competitors are marketing products as environmentally friendly.

In developing constructs to assess the level of stakeholder pressure, it is important to recognise that the respondent's perception of stakeholder pressure as opposed to the actual level of stakeholder pressure may be what gets captured (Gualandris et al., 2015; Henriques and Sadorsky, 1999). Internal stakeholders' perceptions of external pressures is an important consideration as it is often their perceptions that lead them to respond in particular ways. However, to further confirm the existence of competitive environmental pressures within the UK food industry context, other sources were used to generate confidence that the levels of 
customer pressure perceived by responding managers is consistent with reality. Secondary data from online sources such as the Food and Drink Federation (FDF) and the Department for Environment, Food and Rural Affairs (DEFRA) was used to provide information on environmental challenges and pressures within the UK food industry context. These sources were consulted along with studies assessing environmental concerns in the food industry context (Maloni and Brown, 2006; Pullman et al., 2009) throughout the development of the measures for the study and provided support for the existence of competitive environmental pressures within the research context.

\section{Dependent variables}

The measure for upstream environmental practices with suppliers was adapted from Paulraj (2008). This measure is broken into three key constructs, namely, supplier selection, supplier monitoring and supplier collaboration. Supplier selection was measured using a four-item scale whereby managers indicated the extent to which they select suppliers based on their environmental competence, ability to support the focal company's environmental objectives, their environmental performance and their ability to produce environmentally friendly goods. Supplier monitoring was measured using a three-item scale whereby managers indicated the extent to which they conduct environmental audits with suppliers, periodically evaluate suppliers' environmental practices and make site visits for the purpose of supporting improvements in the environmental performance of suppliers. Supplier collaboration was measured using a four-item scale whereby managers indicated the extent to which they collaborate with suppliers to improve their waste reduction initiatives, to promote cleaner production, to encourage suppliers to be more efficient in cutting back waste and to achieve environmental objectives. 
Validity and reliability

In order to assess the effectiveness of each of the scales as measures of their overall construct, a series of factor analyses using Varimax rotation was used. Further analyses using Bartlett's test for spherecity and Kaiser Meyer Olkin's (KMO) test were also conducted to assess the significance and strength of relationships among the different items. Exploratory, rather than confirmatory factor analysis was used as a number of the items were adapted from pre-existing measures and tailored for the food industry context from which the data were collected. Further, one new measure was developed to capture the construct of competitive pressure and thus, had not been validated by any previous studies. The scales were rotated in sets of three along with other scales that were not closely related in terms of what they assess. In order to keep the three upstream supplier practices separate in these analyses, a total of three rotations were conducted with one of the respective supplier practices included alongside proactive environmental strategy and competitive pressure in each rotation. In each case, the KMO scores were above 0.8 with highly significant Bartlett's test of sphericity figures $(p<.001)$, indicating that the items were suitable for factor analysis. In all of the analyses, three-factor solutions were suggested with eigenvalues above 1 and a high level of variance explained (>70\%). Further, all of the standardised loadings were statistically significant and above the .60 threshold, meeting the requirements for convergence validity (Hair et al., 2006). The requirements for discriminant validity were also met as no cross-loading factors above 0.4 were identified.

Common method bias can be a concern in cases where only one key informant from each company completes a survey. To assess for common method bias, Harman's single-factor test was used (Podsakoff et al., 2003). This test seeks to identify whether a single-factor solution provides a better indicator for all the items than the suggested multi-factor 
measurement model. Both the percentage of variance explained in the single-factor analysis and the significance of the difference were examined and no concerns were raised. Further, a correlation matrix was developed and examined using an unrelated variable as a baseline. High correlation coefficients (above .90) for the study's constructs with the baseline variable may give indication that common method bias is a concern (Bagozzi et al., 1991; Tachizawa et al., 2015). No concerns were raised in this analysis. To assess the reliability of each of the measures, Cronbach Alpha scores were also calculated. These values ranged from 0.83 to 0.94 indicating a high level of measurement reliability (Hair et al., 2006). Considered together, the results from these analyses give confidence that the items are representative of their overall constructs.

\section{Control variables}

Five control variables were included in each of the regression models in order to control for organizational characteristics relating to firm size and sub-industry group. Firm size was measured using a logarithm of the number of employees. Sub-industry was incorporated into the regression models using a series of four dummy variables, namely, processed food, beverage, meat and dairy. These control variables were included in the first step of all of the regression analyses. A number of environmental management studies highlight the potential for firm size to influence environmental efforts suggesting that larger companies may have more capital to invest in environmental practices than smaller companies (Chan, 2005; Darnall et al., 2010; Gonzalez-Benito and Gonzalez-Benito, 2006). Further, potential industry effects are prominently noted in the literature on environmental management (e.g. Marshall et al., 2015). Thus, it was important to control for the potential influence of these variables on the results in each of the regression models. 


\section{Data Analysis and Results}

Hierarchical regression analysis was used to test the theoretical model and hypotheses. Prior to this, a series of assumption tests were conducted to ensure that the variables met the requirements for regression analysis (Greene, 2011; Hair et al., 2006). First, all of the independent variables were mean-centred to avoid the problem of multicollinearity. In addition to this, the variance inflation factor (VIF) and tolerance values were examined to assess for multicollinearity. None of the values fell outside of the recommended intervals giving confidence that multicollinearity does not pose a concern for the data. Further residual diagnostic tests, univariate and graphical analyses were used to confirm the suitability of the data for regression analysis (Greene, 2011). A total of six regression models were run in two sets of three. The first set tests hypothesis 1 by assessing the influence of a proactive environmental strategy on the three upstream supplier practice variables (see Table 1). The second set tests hypotheses 2 , and 3 by assessing the influence of competitive pressure on these three practices as well as the mediating influence of a proactive environmental strategy on the relationship between competitive pressure and upstream environmental practices (see Table 2). A separate regression was run to test the relationship between competitive pressure and proactive strategy, which is also included in Table 2.

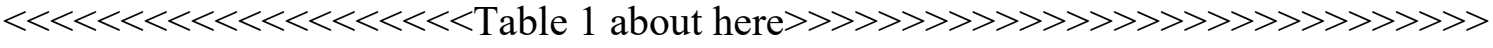

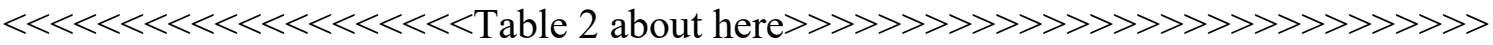




\section{Hypothesis testing}

In order to test hypothesis 1 which proposes a direct relationship between a proactive environmental strategy and upstream environmental practices, three two-step regression models were run. The control variables were included in the first step and the variable proactive environmental strategy was included as the independent variable in the second step. The results are outlined in Table 1. None of the control variables appear to exert a significant influence on any of the upstream practices. Inclusion of proactive environmental strategy as the independent variable generates a change in $R^{2}$ of over $23 \%$ in each of the three regressions, indicating that the inclusion of this variable substantially improves the model. Further, the highly significant correlation coefficients for proactive environmental strategy in each model ( $\beta=.49, p<.001$, $\beta=.49, p<.001$ and $\beta=.54, p<.001$ respectively) provide strong support for hypothesis 1 .

Hypotheses 2 and 3 consider the independent influence of competitive pressure on proactive environmental strategy and upstream environmental practices. This was tested by including competitive pressure as the independent variable at step 2 in the second set of regression models (Table 2). This generated a small but significant increase in the variance explained in each model. The correlation coefficient for the link between competitive pressure and proactive strategy was strong and highly significant $(\beta=.31, p<.001)$, providing support for hypothesis 2 . The correlation coefficients for the link between competitive pressure and supplier practices were all strong and highly significant $(\beta=.31, p<.001, \beta=.24, p<.001$ and $\beta=.35, p<.001$ respectively), providing support for hypothesis 3 .

Step 3 of the same models includes proactive environmental strategy as a mediating variable and assesses for the mediating effects proposed by hypothesis 4 . Three conditions are required for mediation to exist; (1) the independent variable must affect the mediator; (2) the independent variable must affect the dependent variable and; (3) the mediator must affect the 
dependent variable (Baron and Kenny, 1986). The influence of competitive pressure on proactive environmental strategy was confirmed in the first analysis in Table 2, satisfying the requirements of condition 1 . Condition 2 is supported through the results for step 2 of the mediation regressions whereby a significant link between competitive pressure and each of the practices is confirmed. Condition 3 is satisfied in all three cases as strong support for a link between proactive environmental strategy and each of the practices is generated $(\beta=.43$, $p<.001, \beta=.46, p<.001$ and $\beta=.48, p<.001$ respectively).

In the case of both supplier selection and supplier collaboration, the mediating effect appears to be partial as the influence of competitive pressure is reduced in both size and significance, but still remains significant. In the case of supplier monitoring, the results support a fully mediated relationship as the influence of competitive pressure on the outcome becomes non-significant. To further assess the mediating relationships identified in the results, Sobel's test for mediation was conducted (Preacher and Hayes, 2004). The positive and highly significant Sobel test results $(2.83,2.87$ and $2.93 p<.005$ respectively) provide further support for the mediating effects identified. Because partial rather than full mediation appears to exist in two cases, hypothesis 4 receives partial support and cannot be fully accepted. Further discussion of these results and their relationship to the environmental operations and supply chain literature is presented in the following section.

\section{Discussion}

This study developed and tested a set of hypotheses grounded in stakeholder theory to examine the influence of external competitive pressure on internal strategic response and the implementation of upstream environmental practices. First, the independent influences of competitive pressure and a proactive environmental strategy on these practices were assessed. 
Second, the combined influence of these two drivers was assessed. Strong support was obtained for most of the hypothesised relationships. The following discussion considers the key findings and their implications for both theory and practice.

Firstly, support is provided for a direct and positive relationship between a proactive environmental strategy and upstream environmental practices, consistent with hypothesis 1 . While many studies suggest that environmentally proactive companies may express their commitment to the environment through practices both internally and at the supply chain level (Hart and Dowell, 2011; Lopez-Gamero et al., 2009; Zailani et al., 2012), the influence of a proactive environmental strategy on environmental practices has not been extensively assessed. The strategic response to environmental concerns and challenges within companies reflects the viewpoints of internal stakeholders such as directors, managers and employees (Bowen et al., 2001; Buysse and Verbeke, 2003; Henriques and Sadorsky, 1999). Thus, a proactive response suggests a level of commitment from internal stakeholders in addressing the environmental impact of their production processes. Extension of environmental practices to the supply chain level is indicative of higher levels of commitment from internal stakeholders (Graham and Potter, 2015; Hart, 1995; Hart and Dowell, 2011).

Recent studies call for more explicit empirical testing of proactive environmental strategy as an independent construct to enable better understanding of its practical implementation (Akin-Ates et al., 2012; De Burgos-Giminez et al., 2014). The findings from this study respond to this call and build upon results from the few empirical studies that assess the link between a proactive strategy and environmental supply chain practices (Bowen et al., 2001; Graham and Potter, 2015). The upstream focus on supplier practices suggests that a proactive strategy may play an important role in the implementation of environmental practices at this particular stage in the supply chain. 
Support was also generated for hypotheses 2 and 3, suggesting that competitive pressure may influence both the adoption of a proactive environmental strategy and its practical implementation through practices upstream in the supply chain. This is consistent with a number of studies that highlight the influence of external stakeholder pressure on environmental strategies and practices (Buysse and Verbeke, 2003; Garces-Ayerbe et al., 2012; Zailani et al., 2012). A number of empirical studies note that higher levels of external pressure may lead to the development of more proactive strategies and practices (Darnall et al., 2008; Garces-Ayerbe et al., 2012).

Other studies develop more specific conclusions in relation to sources of external pressure that influence the adoption of proactive strategies and practices, noting that competitive may be more influential than coercive pressures (Bansal, 2005; Buysse and Verbeke, 2003; Henriques and Sadorsky, 1999; Paulraj, 2008). For example, coercive pressures deriving from regulatory stakeholder groups are likely to have more of an influence on companies developing a reactive environmental strategy. A reactive strategic response implies that a low level of importance is given to environmental concerns, thus, companies developing this response are more inclined to meet the minimum requirements and expectations deriving from regulatory stakeholders (Buysse and Verbeke, 2003). On the other hand, companies who are more proactive may perceive the potential for competitive benefits to emerge from environmental efforts and therefore be interested in the level of environmental activity taking place within their external environment (Hart, 1995; Tachizawa et al., 2015). The results from this study provide empirical support for the influence of competitive pressure on the development of a proactive environmental strategy and its practical implementation upstream in the supply chain.

Some support was also obtained for the combined influence of external competitive pressure and proactive strategy on the implementation of environmental supplier practices, 
consistent with hypothesis 4 . This suggests that internal strategy plays an important role in the translation of external environmental pressures into a practical environmental response. This builds upon a number of recent studies that examine the combined influence of external pressures and internal factors such as training (Sarkis et al., 2010), strategy (Zailani et al., 2012) and leadership (Dubey et al., 2015) on practical environmental response. This highlights the importance of the response developed by internal stakeholders to the pressures deriving from external stakeholders. Thus, there is more to the relationship between stakeholder pressures and practical response than various external groups influencing companies to adopt particular strategies and practices. Further, the results in support of a direct relationship between proactive strategy and upstream practices were stronger in both size and significance than the results for a direct link between competitive pressure and the same practices. This suggests that the role of the internal stakeholders in developing a strategic response to external pressures provides a stronger explanation for the adoption of environmental practices than external pressures alone. This may also explain the heterogeneity in the adoption of environmental practices across different companies. Thus, the extent to which companies develop a practical response to the external pressures that they all face depends largely on the strategic response developed by internal stakeholder groups.

The results support full mediation in the case of supplier monitoring, suggesting that the companies in the sample may implement this practice in response to competitor pressure when they also adopt a proactive environmental strategy. In the case of supplier selection and collaboration, the influence of competitive pressure is substantially decreased where a proactive strategy exists, suggesting that the implementation of these practices in response to external pressure, is largely determined by the environmental strategy adopted, but may still be directly influenced by competitive pressure. These results highlight the importance of strategy in determining the level of practical response to external pressures at the supply chain level. 
Existing studies that assess combined internal and external influences appear to address the internal, operations level (Dubey et al., 2015; Zailani et al., 2012). These studies confirm that certain stakeholder pressures have a combined influence with internal factors in generating a practical response at this level. Beyond this, no studies appear to consider these combined influences in generating a practical response at the supply chain level. Thus, the findings from this study build upon these studies by extending these influences to practices at the supply chain level.

\section{Theoretical implications}

This study generates a number of important theoretical contributions. First, it contributes to the broad discussion on antecedents of environmental strategies and practices (Buysse and Verbeke, 2003; Dubey et al., 2015; Paulraj, 2008; Zailani et al., 2012). Within this discussion, a range of internal and external factors have been assessed, often independently (Darnall et al., 2008; Garces-Ayerbe et al., 2012; Tachizawa et al., 2015). Through considering the independent and combined influences of external and internal factors on upstream environmental practices, this study extends and builds upon the existing antecedent discussion. It highlights proactive strategy and competitive pressure as important factors in developing a practical environmental response at the supply chain level. Second, it extends the application of stakeholder theory in the context of environmental management by considering the influence of the underexplored dimension of competitor pressure as well as the response to this pressure from internal stakeholders (Hofer et al., 2012; Tachizawa et al., 2015; Zailani et al., 2012). Broader consideration of the influence of internal and external stakeholders has been encouraged in recent studies (Sarkis et al., 2010; Tachizawa et al., 2015; Zailani et al., 2012). This study provides support for the important role played by stakeholders both within and 
outside of the company in driving a practical environmental response at the supply chain level. This sheds light on the heterogeneous responses to external pressures through the lens of stakeholder theory as the importance of internal stakeholder perceptions to external pressures is highlighted. Thus, practical responses to external pressures are largely a result of the viewpoints of internal, strategy developing stakeholders with control over the level of environmental investment.

Third, the quantitative analysis enables the empirical testing of some of the relationships highlighted in an earlier study by Paulraj (2008). This study used an exploratory cluster analysis approach to identify some of the key relationships between external pressures, strategy and practices. Findings from the current study provide confirmation for some of these relationships and validation of the supplier practice constructs developed in Paulraj's (2008) study. Fourth, it responds to calls for more research to be conducted in the context of the food industry which faces a range of unique environmental challenges (Darkow et al., 2015; Mattas and Tsakiridou, 2010; New, 2015; Pullman and Wikoff, 2017).

\section{Managerial implications}

The findings also have important implications for organisations and managers. First, it is evident that food manufacturing companies in the UK are facing mimetic pressures in their external environment as competitors increasingly adopt environmental practices. These pressures may generate an increase in the adoption of proactive environmental strategies and practices. Second, the framework provides some guidance to managers on how companies develop their practical response to competitive pressures at the supply chain level. This sheds light on some of the key environmental practices with suppliers being adopted within the UK food industry. Third, the results suggest that internal strategy plays a more important role in 
the adoption of environmental supply chain practices than external pressure. This suggests that strategic commitment to the environment may generate a stronger practical response than competitive pressure. Thus, if managers are seeking to extend environmental efforts to the supply chain level, a proactive strategy may be an important consideration for them.

\section{Limitations and future research directions}

This study contains some limitations that need to be acknowledged. First, the data collected for this study is cross-sectional in nature and does incorporate any time dimension. It may be useful for future studies to try to identify the length of time the company has faced external pressures and when they implemented strategies and practices in response. Further, it would be useful to know how long they have had their internal environmental strategy in place in comparison to how long they have implemented the supply chain practices. Second, while pre-existing constructs were used to measure the constructs, where available, some of these were adapted or newly developed for the study. While all measures appeared to meet the requirements for reliability and validity, further applications in future research will enhance their effectiveness as measures.

As companies continue to face increasing levels of pressure to be more environmentally responsible, it is useful to seek to understand the heterogeneous responses being pursued. Future studies should continue to assess various internal and external factors that might influence how a company responds to environmental challenges. A similar study to this one could be conducted across other industries to identify if the same findings emerge. Further, it may be useful to consider the specific drivers of more reactive strategies and how they translate into practice. 


\section{Conclusion}

The aim of this study was to assess the influence of internal and external drivers on the adoption of upstream environmental practices with suppliers. Stakeholder theory provided the theoretical lens. The findings generate some novel insights into the key drivers of environmental supply chain practices. First, the practical implementation of a proactive environmental strategy through three environmental supplier practices was confirmed. Second, the influence of competitive stakeholder pressures on the adoption and practical implementation of a proactive strategy was confirmed. Third, the combined influence of external competitive pressure and internal strategy on upstream environmental practices was confirmed. The findings are generalizable to the food industry and provide strong support for the relationships hypothesised in the article. Considered together, the findings suggest that internal strategy is a stronger driver of environmental supplier practices than external competitive pressure. Further, internal strategy and competitive pressure exert a combined influence on supplier practices to an extent. Thus, both are important factors in the development of environmental supply chain practices, but internal strategy may be a more important consideration for companies seeking to implement these practices.

\section{Acknowledgements}

The author acknowledges financial support from the Department of Education and Learning (DEL) in Northern Ireland and the Assured Safe and Traceable Food (ASSET) Research Project at Queen's University Belfast. 


\begin{tabular}{l} 
Items \\
\hline Proactive Environmental Strategy \\
Our management gives high priority to environmental issues \\
The top managers in our business unit give environmental issues a high priority \\
We lead our industry on environmental issues \\
We always attempt to go beyond basic compliance with laws and regulations on environmental issues \\
We effectively manage the environmental risks which affect our business \\
Competitive Pressure \\
Environmental concerns are being taken seriously by our competitors \\
Competitors have increasingly implemented environmental practices \\
Our competitors are marketing products as environmentally friendly \\
Supplier Selection \\
We select suppliers based on their environmental competence \\
Suppliers are selected based on their ability to support our environmental objectives \\
We select suppliers based on their environmental performance \\
We select suppliers based on their ability to develop environmentally friendly produce \\
Supplier Monitoring \\
We conduct regular environmental audits into our suppliers' internal operations \\
We periodically evaluate our suppliers' environmentally friendly practices \\
We make site visits to suppliers' premises to help them improve their eco-performance \\
Supplier Collaboration \\
We cooperate with our suppliers to improve their waste reduction initiatives \\
We cooperate with our suppliers for cleaner production \\
We encourage our suppliers to be more efficient in cutting back waste \\
We cooperate with our suppliers to achieve environmental objectives \\
\hline
\end{tabular}

\section{References}

Agustina, D., C. Lee and R. Piplani (2014). Vehicle scheduling and routing at a cross docking center for food supply chains, International Journal of Production Economics, 152: 29-41.

Akin-Ates, M., J. Bloemhof, E. Raaij and F. Wynstra (2012). Proactive environmental strategy in a supply chain context: the mediating role of investments. International Journal of Production Research, 50 (4): 1079-1095.

Armstrong, S. J. and T. S. Overton (1977). Estimating non-response bias in mail surveys. Journal of Marketing Research, 14(August): 396-402.

Awaysheh, A. and Klassen, R.D. (2010). The impact of supply chain structure on the use of supplier socially responsible practices, International Journal of Operations \& Production Management, 30 (12): 1246-1268.

Ayuso, S., M. Rodriguez, R. Garcia-Castro and M. Arino. (2014). Maximising stakeholders' interests: An empirical analysis of the stakeholder approach to corporate governance. Business and Society, 53 (3): 414-439.

Bagozzi, R., Y. Yi, and L. Phillips (1991). Assessing construct validity in organizational research. Administrative Science Quarterly, 36: 421-458.

Bansal, P. (2005). Evolving sustainability: A longitudinal study of corporate sustainable development. Strategic Management Journal, 26: 197-218.

Baron, R. and Kenny, D. (1986). The moderator-mediator variable distinction in social psychological research: Conceptual, strategic and statistical considerations. Journal of Personality and Social Psychology, 51 (6): 1173-1182.

Bode, C. and S. Wagner (2015). Structural drivers of upstream supply chain complexity and the frequency of supply chain disruptions. Journal of Operations Management, 36: 215-228.

Bowen, F., P. Cousins, R. Lamming and A. Faruk (2001). The role of supply management capabilities in green supply. Production and Operations Management, 10(2): 174-189.

Buysse, K. and A. Verbeke (2003). Proactive environmental strategies: A stakeholder management perspective. Strategic Management Journal, 24: 453-470. 
Compagni, A., V. Mele and D. Ravasi (2015). How early implementations influence later adoptions of innovation: Social positioning and skill reproduction in the diffusion of robotic surgery. Academy of Management Journal, 58 (1): 242-278.

Chen, I. and Paulraj, A. (2004). Towards a theory of supply chain management: the constructs and measurements. Journal of Operations Management, 22(2): 119-150.

Daily, B., Bishop, J. and Massoud, J. (2012). The role of training and empowerment in environmental performance. International Journal of Operations and Production Management, 32 (5): 631-647.

Darnall, N., I. Henriques and P. Sadorsky (2010). Adopting Proactive Environmental Strategy: The influence of stakeholders and firm size. Journal of Management Studies, 47(6): 1072-1094.

Darnall, N., J. G. Jolley and R. Handfield (2008). Environmental management systems and green supply chain management: complements or contradictions. Business Strategy and the Environment, 17(1): 30 .

Darkow, I., B. Foerster and H. von der Gracht. (2015). Sustainability in food service supply chains: future expectations from European industry experts toward the environmental perspective. Supply Chain Management: An International Journal, 20 (2): 163-178.

De Burgos-Jiminez, J., Vazquez-Brust, D. and Plaza-Ubeda, J. (2014). Environmental protection and financial performance: an empirical analysis in Wales, International Journal of Production and Operations Management, 33 (8): 981-1018.

DEFRA (2017) Department for Environment, Food and Rural Affairs, http://www.defra.gov.uk/ , accessed 29/5/2017.

Delmas, M., V. Hoffmann and M. Kuss. (2011). Under the tip of the iceberg: Absorptive capacity, environmental strategy and competitive advantage. Business and Society, 50 (1): 116-154.

Dillman, D. (2007). Mail and Internet Surveys: The Tailored Design Method. New Jersey, John Wiley and Sons Inc.

DiMaggio, P. and W. Powell (1983). The iron cage revisited: institutional isomorphism and collective rationality in organisational fields. American Sociological Review, 48: 147-160.

Drucker, D. (2005). Doing Research: Methods of Inquiry for Conflict Analysis. California, Sage Publications.

Dubey, R., A. Gunasekaran and S. Ali (2015). Exploring the relationship between leadership, operational practices, institutional pressures and environmental performance: A framework for green supply chain. International Journal of Production Economics, 160: 120-132.

FDF (2017), Food and Drink Federation, http://www.fdf.org.uk/ , accessed 29/05/2017

Forza, C. (2002). Survey research in operations management: a process-based perspective. International Journal of Operations \& Production Management, 22(2): 152-194.

Garces-Ayerbe, C., P. Rivera-Torres and J. Murillo-Luna (2012). Stakeholder pressure and environmental proactivity: Moderating effect of competitive advantage expectations. Management Decision, 50 (2): 189-206.

Gondivan, K. Sustainable consumption and production in the food supply chain: A conceptual framework. International Journal of Production Economics, article in press.

Gonzalez-Benito, J. and O. Gonzalez-Benito (2006). A review of determinant factors of environmental proactivity. Business Strategy and the Environment, 15: 87-102.

Graham, S. and A. Potter (2015). Environmental operations management and its links with proactivity and performance: A study of the UK food industry. International Journal of Production Economics, 170: $146-159$.

Greene, W. H. (2011). Econometric Analysis. Pearson Education, Harlow, England.

Gualandris, J., R. Klassen, S. Vachon and M. Kalchschmidt (2015). Sustainable evaluation and verification in supply chains: Aligning and leveraging accountability to stakeholders. Journal of Operations Management, 38: 1-13.

Guenther, E., T. Guenther, F. Schiemann and G. Weber. (2016). Stakeholder relevance for reporting: Explanatory factors of carbon disclosure. Business and Society, 55 (3): 361-397.

Hair, J. F., W. C. Black, B. Babin, R. Anderson and R. Tatham (2006). Multivariate Data Analysis, Pearson Prentice Hall.

Hamann, R., J. Smith, P. Tashman and R. Marshall. (2015). Why do SMEs go green $>$ An analysis of wine firms in South Africa. Business and Society: 1-34.

Hart, S. and G. Dowell (2011). A natural-resource-based view of the firm: Fifteen years after. Journal of Management, 37 (5): 1464-1479. 
Hart, S. (1995). A natural-resource-based view of the firm. Academy of Management Review, 20(4): 9861014.

Henriques, I. and P. Sadorsky (1999). The relationship between environmental commitment and managerial perceptions of stakeholder importance. Academy of Management Journal, 42(1): 87-99.

Heras-Saizarbitoria, I., G. Landin and J. Molina-Azorin (2011). Do drivers matter for the benefits of ISO 14001? International Journal of Operations and Production Management, 31 (2): 192-215

Hofer, C., D. Cantor and J. Dai (2012). The competitive determinants of a firm's environmental management activities: Evidence from US manufacturing industries. Journal of Operations Management, 30: 6984.

Hoffman, A. (2001). Linking organizational and field-level analyses. Organization \& Environment, 14 (2): 133-156.

Kannan, D. (2017). Role of multiple stakeholders and the critical success factor theory for the sustainable supplier selection process. International Journal of Production Economics, article in press http://dx.doi.org/10.1016/i.ijpe.2017.02.020

Kumar, S., Teichman, S., Timpernagel. T. (2012). A green supply chain is a requirement for profitability. International Journal of Production Research 50 (5): 1278-1296.

Li, D., Wang, X., Chan, H. and Manzini, R. (2014). Editorial: Sustainable food supply chain management. International Journal of Production Economics, 152: 1-8.

Liu, Y., Q. Zhu and S. Seuring (2017). Linking capabilities to green operations strategies: The moderating role of corporate environmental proactivity. International Journal of Production Economics, 187: 182-195.

Liu, H., W. Ke, K. Wei, J. Gu and H. Chen (2010). The role of institutional pressures and organizational culture in the firm's intention to adopt internet-enabled supply chain management systems. Journal of Operations Management, 28: 372-384.

Lopez-Gamero, M., Molina-Azorin, J. and Claver-Cortes, E. (2009). The whole relationship between environmental variables and firm performance: Competitive advantage and firm resources as mediator variables, Journal of Environmental Management, 90: 3110-3121.

Marshall, D., L. McCarthy, P. McGrath and M. Claudy. (2015). Going above and beyond: how sustainability culture and entrepreneurial orientation drive social sustainability supply chain practice adoption. Supply Chain Management: An International Journal, 20 (4): 434-454.

Mattas, K. and E. Tsakiridou (2010). Shedding fresh light on food industry's role: the recession's aftermath. Trends in Food Science and Technology, 21: 212-216.

Moriarty, J. (2014). The connection between stakeholder theory and stakeholder democracy: An excavation and defense. Business and Society, 53 (6): 820-852.

Murillo-Luna, J., C. Garces-Ayerbe and P. Riverra-Torres (2011). Barriers to the adoption of proactive environmental strategies. Journal of Cleaner Production, 19: 1417-1425.

New, S. (2015). Modern slavery and the supply chain: the limits of corporate social responsibility? Supply Chain Management: An International Journal, 20 (6): 697-707.

Pagell, M. and Gobeli, D. (2009), How plant managers' experiences and attitudes toward sustainability relate to operational performance, Production and Operations Management, Vol. 8 No. 3, pp. 278-299.

Paulraj, A. (2008). Environmental motivations: a classification scheme and its impact on environmental strategies. Business Strategy and the Environment.

Podsakoff, P., S. MacKenzie., J. Lee and N. Podsakoff (2003). Common method biases in behavioral research: A critical review of the literature and recommended remedies. Journal of Applied Psychology, 88, 879-903.

Preacher, K. and Hayes, A. (2004). SPSS and SAS procedures for estimating indirect effects in simple mediation models. Behaviour research methods, Instruments \& Computers, 36 (4): 717-731.

Pullman, M. and R. Wikoff (2017). Institutional sustainable purchasing priorities: Stakeholder perceptions vs environmental reality. International Journal of Operations and Production Management, 37 (2): 162-181.

Sarkis, J., P. Gonzalez-Torre and B. Adenso-Dias (2010). Stakeholder pressure and the adoption of environmental practices: The mediating effect of training. Journal of Operations Management, 28: 163-176.

Simpson, D. and R. Sroufe (2014). Stakeholders, reward expectations and firms' use of the ISO 14001 management standard. International Journal of Operation and Production Management, 34 (7): 830-852. 
Su, W. and E. Tsang (2015). Product diversification and financial performance: The moderating role of secondary stakeholders. Academy of Management Journal, 58 (4): 1128-1148.

Tachizawa, E., C. Giminez and V. Sierra. (2015). Green supply chain management approaches: drivers and performance implications. International Journal of Operation and Production Management, 35 (11): 1546-1566.

Vachon, S. and Klassen, R. (2008). Environmental management and manufacturing performance: The role of collaboration in the supply chain. International Journal of Production Economics, 111: 299-315.

Wu, G., J. Ding and P. Chen (2012). The effects of GSCM drivers and institutional pressures on GSCM practices in Taiwan's textile and apparel industry. International Journal of Production Economics, 135: 618-636.

Zailani, S., Eltayeb, T., Hsu, C., Tan, K. (2012). The impact of external institutional drivers and internal strategy on environmental performance. International Journal of Operations and Production Management, 32 (6): 721-745.

Zhu, Q., Sarkis, J., Lai, K. (2012). Examining the effects of green supply chain improvements and their mediations on performance improvements. International Journal of Production Research, 50 (5): 1377-1394. 
Table 1- The influence of a proactive environmental strategy on upstream environmental practices

SUPPLIER SELECTION

SUPPLIER MONITORING

SUPPLIER COLLABORATION

MODEL 1

MODEL 1

MODEL 2

MODEL 1 MODEL 2

Control Variables:

Firm Size

Processed Food Industry

$\begin{array}{ll}-.02 & -.10 \\ -.03 & -.08\end{array}$

Beverage Industry

Meat Industry

Dairy Industry

$-.03 \quad-.08$

$\begin{array}{ll}-.08 & -.07\end{array}$

$-.06 \quad-.05$

$.01 \quad-.00$

$\begin{array}{ll}.07 & -.01 \\ -.07 & -.13\end{array}$

$-.02$

$\begin{array}{ll}-.09 & -.08 \\ -.06 & -.07\end{array}$

Direct Effects:

Proactive environmental strategy

$\begin{array}{llllll} & \mathbf{. 4 9} * * * & & \mathbf{4 9 * *} & & \mathbf{. 5 4} * * * \\ .01 & .23 & .02 & .23 & .01 & .28 \\ .22 & 41.86^{* * *} & .45 & 42.75 * * * & .22 & 55.54 * * * \\ .01 & .24 & .02 & .25 & .01 & .29 \\ -.03 & .20 & -.02 & .21 & -.03 & .26 \\ .22 & 7.21 * * * & .43 & 7.61 * * * & .22 & 9.51 * * * \\ 149 & 149 & 149 & 149 & 149 & 149\end{array}$

\section{$\Delta \mathrm{R}^{2}$}

\section{$\Delta \mathrm{F}$}

Overall $\mathrm{R}^{2}$

Adjusted $\mathrm{R}^{2}$

Overall model $\mathrm{F}$

Note: $* * * \mathrm{p}<0.001,{ }^{* *} \mathrm{p}<.05,{ }^{*} \mathrm{p}<.10$ (one-tailed tests for hypotheses; two-tailed tests for controls; standard errors in parenthesis). Standardized regression coefficients are shown. 


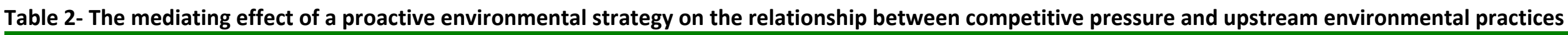

\begin{tabular}{|c|c|c|c|c|c|c|c|c|c|c|c|}
\hline & \multicolumn{2}{|c|}{ PROACTIVE STRATEGY } & \multicolumn{3}{|c|}{$\begin{array}{l}\text { SUPPLIER SELECTION } \\
\end{array}$} & \multicolumn{3}{|c|}{ SUPPLIER MONITORING } & \multicolumn{3}{|c|}{ SUPPLIER COLLABORATION } \\
\hline & MODEL 1 & MODEL 2 & MODEL 1 & MODEL 2 & MODEL 3 & MODEL 1 & MODEL 2 & MODEL 3 & MODEL 1 & MODEL 2 & MODEL 3 \\
\hline Control Variables: & & & & & & & & & & & \\
\hline Firm Size & .16 & .14 & -.02 & -.04 & -.10 & .07 & .05 & -.01 & .02 & .00 & -.06 \\
\hline Processed Food Industry & .11 & .15 & -.03 & .02 & -.05 & -.07 & -.04 & -.11 & -.05 & -.01 & -.08 \\
\hline Beverage Industry & -.01 & -.05 & -.08 & -.13 & -.10 & -.03 & -.06 & -.04 & -.09 & -.15 & -.12 \\
\hline Meat Industry & -.02 & .00 & -.06 & -.05 & -.05 & -.09 & -.08 & -.08 & -.03 & -.01 & -.01 \\
\hline Dairy Industry & .03 & -.01 & .01 & -.02 & -.02 & -.06 & -.09 & -.09 & -.02 & -.07 & -.07 \\
\hline Direct Effects: & & & & & & & & & & & \\
\hline Competitive pressure & & $.31 * * *$ & & $.31 * * *$ & $.18 *$ & & $.24 * * *$ & .10 & & $.35 * * *$ & $.20 * *$ \\
\hline Mediating Effects & & & & & & & & & & & \\
\hline $\begin{array}{l}\text { Proactive environmental } \\
\text { strategy }\end{array}$ & & & & & $.43 * * *$ & & & $.46 * * *$ & & & $.48 * * *$ \\
\hline$\Delta \mathrm{R}^{2}$ & .04 & .09 & .01 & .09 & .16 & .02 & .06 & .18 & .01 & .11 & .20 \\
\hline$\Delta \mathrm{F}$ & 1.18 & $14.49 * * *$ & .22 & $14.00 * * *$ & $31.00 * * *$ & .45 & $8.36 * * *$ & $34.23 * * *$ & .22 & $18.19 * * *$ & $41.47 * * *$ \\
\hline Overall $\mathrm{R}^{2}$ & .04 & .13 & .01 & .10 & .26 & .02 & .07 & .25 & .01 & .12 & .32 \\
\hline Adjusted $\mathrm{R}^{2}$ & .01 & .09 & -.03 & .06 & .22 & -.02 & .03 & .22 & -.03 & .08 & .29 \\
\hline Overall model F & 1.18 & $3.49 * * *$ & .22 & $2.54 * *$ & $7.06^{* * *}$ & .45 & $1.78^{*}$ & $6.78 * * *$ & .22 & $3.24 * * *$ & $9.50 * * *$ \\
\hline $\mathrm{N}$ & 149 & 149 & 149 & 149 & 149 & 149 & 149 & 149 & 149 & 149 & 149 \\
\hline
\end{tabular}


